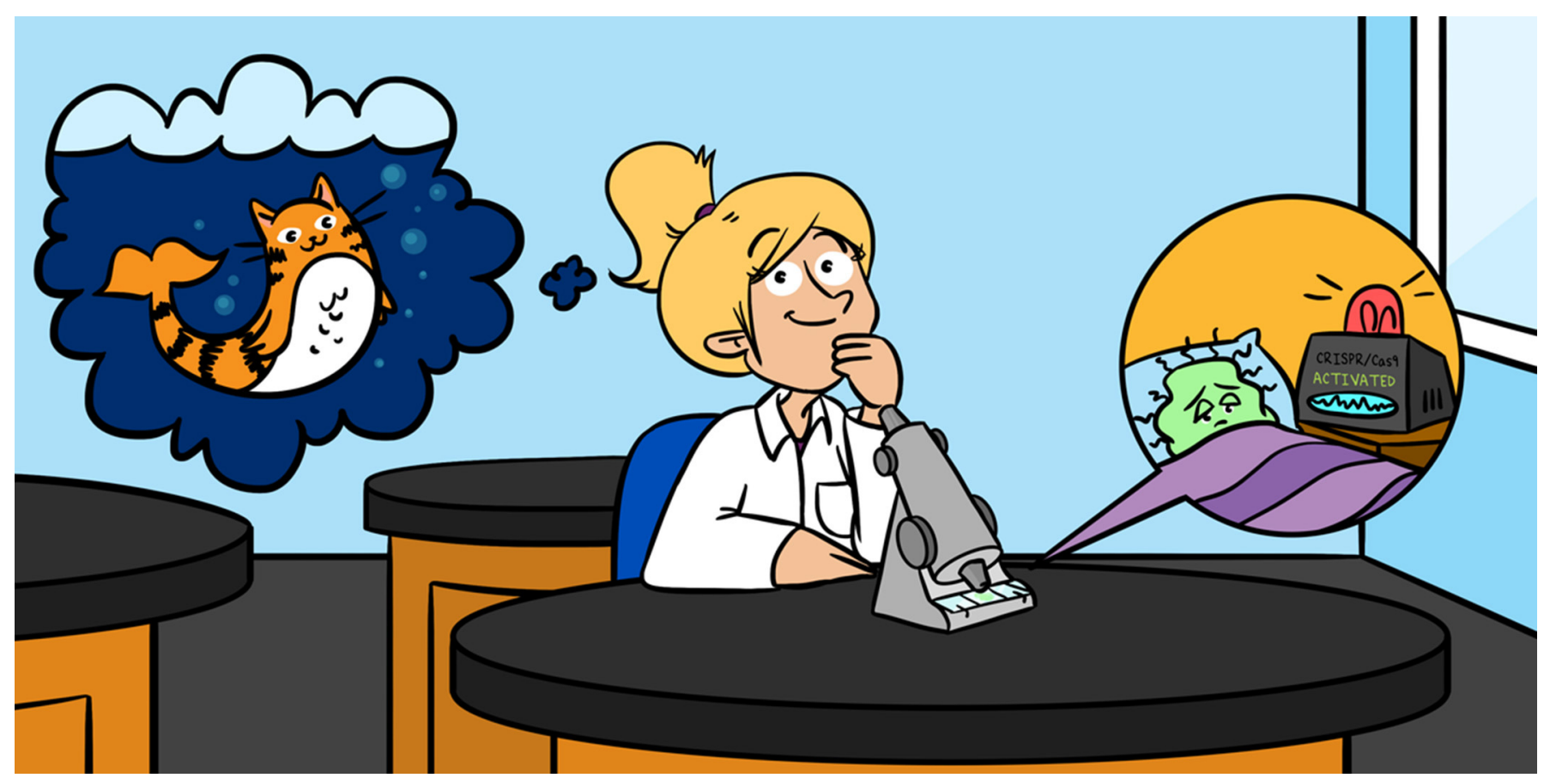

\title{
CRISPR: A NEW WAY FOR SCIENTISTS TO EDIT DNA
}

\section{Elisabeth A. Marnik ${ }^{1,2^{*}}$, Carla Bautista ${ }^{1,3,4,5,6 t}$, Anna Drangowska-Way ${ }^{1,7}$, Caitlin M. A. Simopoulos ${ }^{1,8 t}$ and Thomas J. S. Merritt ${ }^{1,9}$}

${ }^{1}$ Early Career Scientist Communication and Outreach Subcommittee, Genetics Society of America, Rockville, MD, United States ${ }^{2}$ Department of Science, Husson University, Bangor, ME, United States

3 Institut de Biologie Intégrative et des Systèmes (IBIS), Université Laval, Québec, QC, Canada

${ }^{4}$ Département de Biologie, Faculté des Sciences et de Génie, Université Laval, Québec, QC, Canada

${ }^{5}$ Regroupement québécois de recherche sur la fonction, la structure et l'ingénierie des protéines (PROTEO), Université Laval, Québec, QC, Canada

${ }^{6}$ Centre de Recherche en Données Massives (CRDM), Université Laval, Québec, QC, Canada

${ }^{7}$ Department of Biology, College of Arts and Sciences, University of Virginia, Charlottesville, VA, United States

${ }^{8}$ Department of Biochemistry, Microbiology and Immunology, Faculty of Medicine, University of Ottawa, Ottawa, ON, Canada ${ }^{9}$ Department of Chemistry and Biochemistry, Laurentian University, Sudbury, ON, Canada

\section{YOUNG REVIEWERS:}
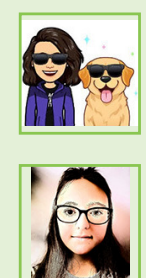

ABIGAIL

AGE: 11

MADDIE

AGE: 12
Just like humans, bacteria can get sick. Some bacteria have a defense system called CRISPR/Cas9 that protects them from infection with viruses. Over the last few years, scientists have adapted this bacterial defense system to be used in the laboratory to alter the DNA of various organisms. This article will explain how CRISPR/Cas9 is used to edit genes and will provide examples of how this technology is useful. Experiments using CRISPR/Cas9 must be carried out ethically, that is, scientists must ensure that all research respects human rights and animal welfare and complies with the law. 
BACTERIOPHAGE

A type of virus that only infects bacteria.

\section{NUCLEOTIDE}

One of the four building blocks that make up DNA. They are called adenine (A), cytosine $(C)$, guanine $(G)$, and thymine $(T)$.

\section{PALINDROMIC} SEQUENCE

A specific order of nucleotides that reads the same, forward or backward. For example, TAGCGAT is a palindromic sequence.

\section{CRISPR/CAS9: THE DEFENSE SYSTEM OF BACTERIA}

No one likes to get sick. We cough, sneeze, have fever, and pain. All these things are signs that the body's defenses, called the immune system, are trying to protect us from tiny, disease-causing invaders, including viruses causing diseases like the common cold or Covid-19. Did you know that viruses can infect many other organisms, too-including tiny bacteria? The viruses that infect bacteria are called bacteriophages. Although it is quite different from the human immune system, bacteria also have a defense system that protects them against infections. This system is called CRISPR/Cas9 [1]. When a bacteriophage infects a bacterium, the virus injects its genetic material into the bacterium. The bacterium recognizes this invader, and with the help of CRISPR/Cas9, cuts the genetic material into pieces to stop the infection. Afterwards, the bacterium keeps a piece of the bacteriophage's genetic material, so if the same bacteriophage infects again, the bacterium can react more quickly to the invader.

\section{WHAT IS CRISPR/CAS9?}

The name CRISPR stands for Clustered Regularly Interspaced Short Palindromic Repeats. This sounds like a mouthful, but keep reading and you will understand this complicated name!

Like all organisms, bacteria contain a genetic material called DNA. DNA is made of four different building blocks, called nucleotides: adenine $(A)$, guanine $(G)$, cytosine $(C)$, and thymine $(T)$. The sequence of these four building blocks is a code for the instructions to create the organism, similar to the way sequences of letters form words. In some places the code forms palindromic sequences, which can be read the same way forward or backward. The word "kayak" is an example of a palindrome. A DNA palindrome could look like TAGCGAT. Just like the word kayak, TAGCGAT reads the same both forward and backward. Now, imagine there were several copies of the TAGCGAT sequence in the DNA. You could call them short palindromic "repeats" because they are repeated. If those palindromic repeats are found in groups throughout the DNA code, then we call them "clustered." Since those palindromic repeats are separated by other DNA sequences, they are called "interspaced." Put everything together, and you just discovered Clustered Regularly Interspaced Short Palindromic Repeats, or CRISPR! Last, Cas-9 is included in the name because it is an important protein used in the CRISPR system, which will be described below.

\section{HOW DOES CRISPR/CAS9 HELP SCIENTISTS?}

You may be wondering why the defense system of bacteria is so important to scientists. Scientists figured out how to use the 
Figure 1

(A) DNA is composed of two strands, wound together to form a shape called a double helix. (B) The DNA strands are made of four building blocks, called nucleotides: adenine $(A)$, thiamine $(T)$, cytosine $(C)$, and guanine (G). (C) Nucleotides are arranged in a specific sequence, which contains the directions for life! (D) Through an intermediary molecule called RNA, the DNA makes proteins that combine to form the organism. If the DNA changes, it changes the protein it codes for, which can cause changes in the organism (created with BioRender.com)

\section{CAS9}

A protein that acts like scissors to cut DNA. This protein is a required part of CRISPR/Ca9 which is why it is included in the name!

\section{GUIDE RNA}

A small RNA strand that leads Cas9 to the location it needs to cut the DNA.

\section{PAM SITE}

A three nucleotide sequence in the order NGG (where $\mathrm{N}$ is an $\mathrm{A}$, $\mathrm{G}, \mathrm{T}$ or $\mathrm{C}$ ). This sequence acts like the dotted line where Cas9 cuts the DNA.

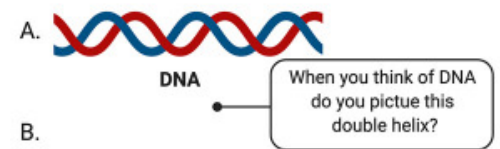

D.

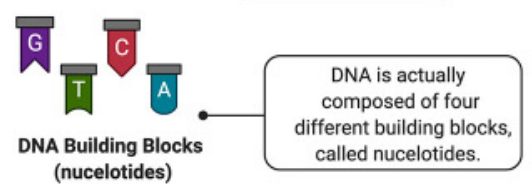

c.

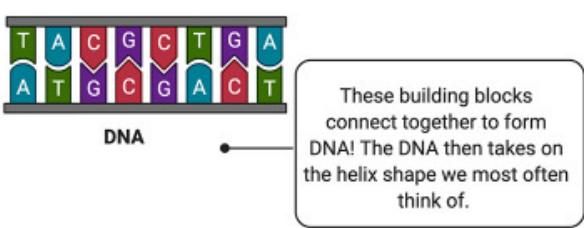

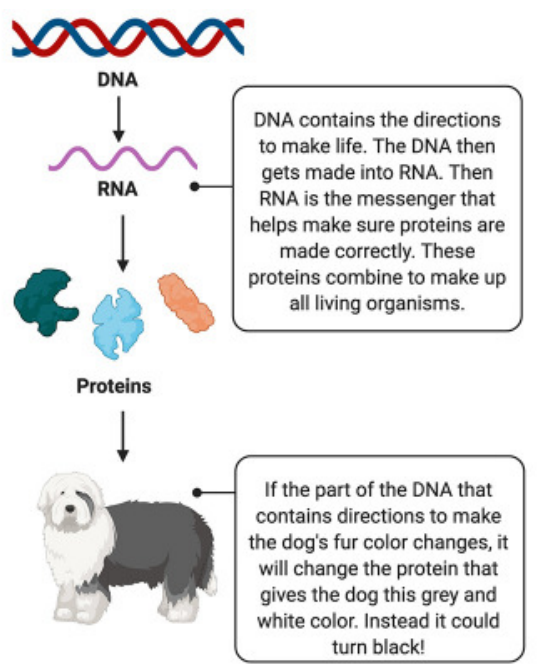

Figure 1

CRISPR/Cas9 system to edit, or change the sequence of, DNA. This discovery of how to use CRISPR/Cas9 in the laboratory was extremely important for the scientific community-so important that, in 2020, two researchers who helped discovered it (Emmanuelle Charpentier and Jennifer A. Doudna) received the most important scientific award-The Nobel Prize in Chemistry.

As we mentioned, the nucleotides that make up DNA form a code that holds the instructions to make the entire organism. Sections of DNA that code for a specific trait, for example the color of a dog's fur, are called genes. Let's say we know which gene controls the color of a dog's fur. If the order of the nucleotides in that gene is changed, the dog's fur color would change. Why? Because we have changed the instructions for making the dog's fur color (Figure 1).

To understand how we use the CRISPR/Cas9 system to edit genes, you must first understand the parts of this system and how they work. First, scientists must know the order of nucleotides, or the sequence, of the gene they are interested in editing. Luckily, there are websites with this information. Once the gene sequence is known, the first piece of the CRISPR/Cas9 system that we must use is a special protein called Cas9. Cas 9 acts like scissors to cut the DNA. Cas9 can cut DNA anywhere, but we only want it to cut the gene we are interested in. Getting the Cas 9 to the right location requires a component called guide RNA, which acts like GPS coordinates directing Cas9 to the sequence we want to cut. We design the guide RNA from the sequence of the gene, so that Cas9 will only cut the DNA at that exact location (Figure 2A). Near the guide RNA is a PAM site, which is a three-nucleotide sequence that acts like the dotted lines showing Cas9 where to cut the DNA. We find a PAM site closest to the area of the DNA we want to cut (Figure 2B). The final component is called a repair template. The repair template is 
Figure 2

Gene editing using CRISPR/Cas9. (A) First, the Cas9 protein is brought to the proper location on the gene we want to change by the guide RNA. (B) The PAM site tells Cas9 where to cut the DNA. (C) The repair template, which contains the change we want to make to the gene, finds the cut area of DNA and is used to fix the DNA. (D) Once the DNA is repaired, it will include the desired changes! (created with BioRender.com).

\section{REPAIR TEMPLATE}

A sequence of DNA the scientist designs to repair the DNA where it was cut by adding, deleting, or changing the DNA.

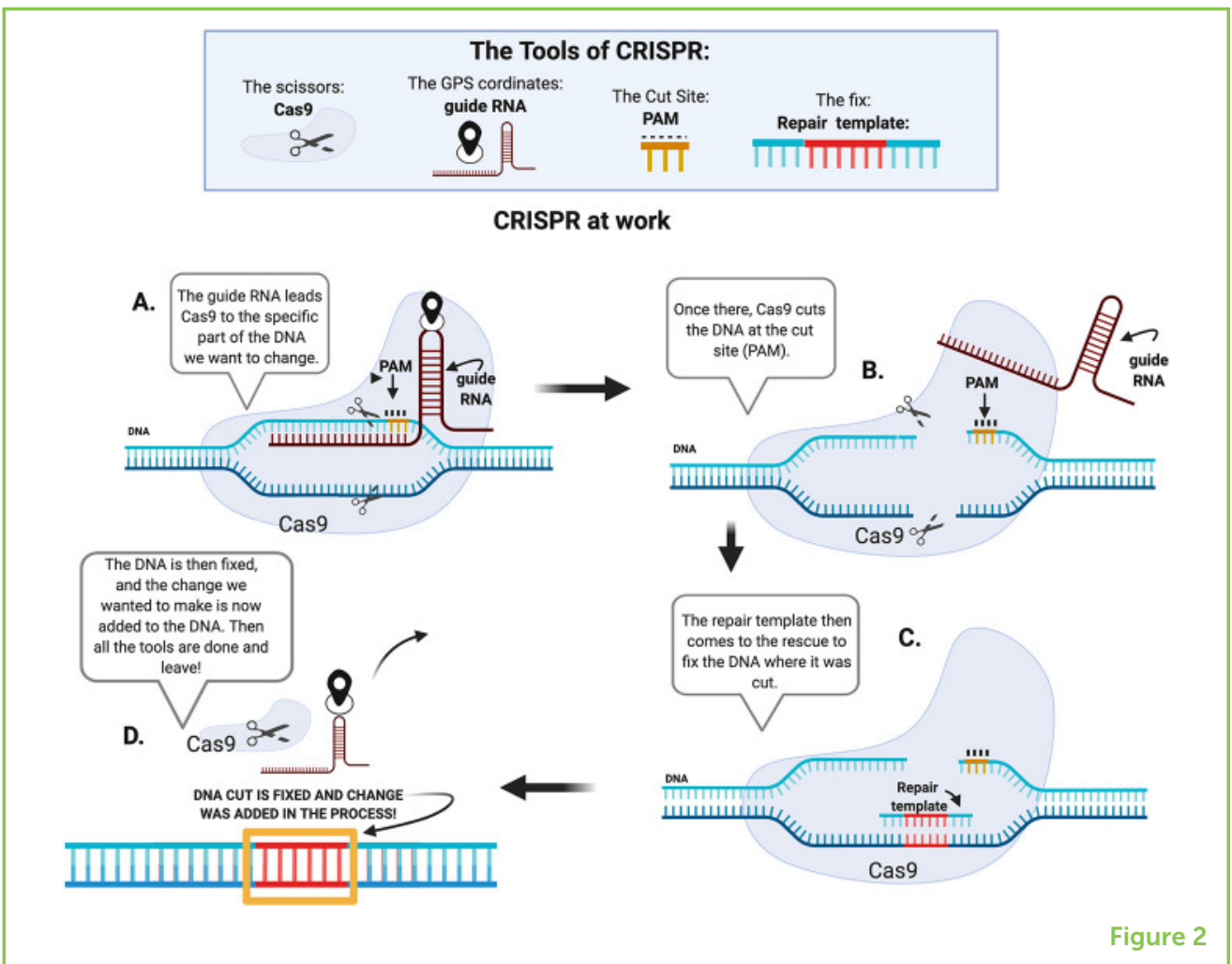

a piece of DNA with the new sequence that we want the gene to have (Figure 2C). Using a repair template, we can copy, paste, add to, or delete parts of the DNA sequence, just like editing sentences in a word document! For example, let's say we wanted to add the nucleotides ATGCTA to our gene. The repair template would contain ATGCTA plus some extra DNA on either side that matches the original gene, to tell the repair template where to go. Then, after the DNA is repaired, the new nucleotides would be pasted into the DNA exactly where we want them to be (Figure 2D), giving us our edited gene.

\section{WHAT KINDS OF THINGS CAN BE STUDIED USING CRISPR?}

Now that scientists better understand the CRISPR/Cas9 gene editing tool, what sorts of things can they do with it? Figure 3 shows some examples. Research using CRISPR is often done on organisms like bacteria, yeast, worms, plants, and mice because they are easy to use in the laboratory [2]. These species can tell scientists a lot about human DNA and how genes function, because some human genes are the same as, or very similar to, genes in other species.

Some human diseases are caused by mistakes in the DNA, which can be passed on over generations. Scientists and physicians are working to use CRISPR/Cas9 to treat diseases by targeting and correcting these DNA mistakes. This type of treatment for diseases is called 
Figure 3

The many uses of CRISPR/Cas9. (A)

Doctors can use

CRISPR/Cas9 as a

treatment for diseases

that are caused by

mistakes in the DNA.

(B) It is possible for researchers to use CRISPR/Cas9 to bring animals like the wooly mammoth back from extinction. (C)

Scientists can create new products, like spicy tomatoes, by using CRISPR/Cas9 to change their DNA. (D) CRISPR can be used for research, to understand the functions of genes (created with

BioRender.com).

\section{GENE THERAPY}

A method of treating diseases that is caused by mutations in the DNA. If we fix the DNA, it can fix the disease.

\section{ETHICS}

A set of rules that makes sure that the work scientists do does not hurt animals or humans.
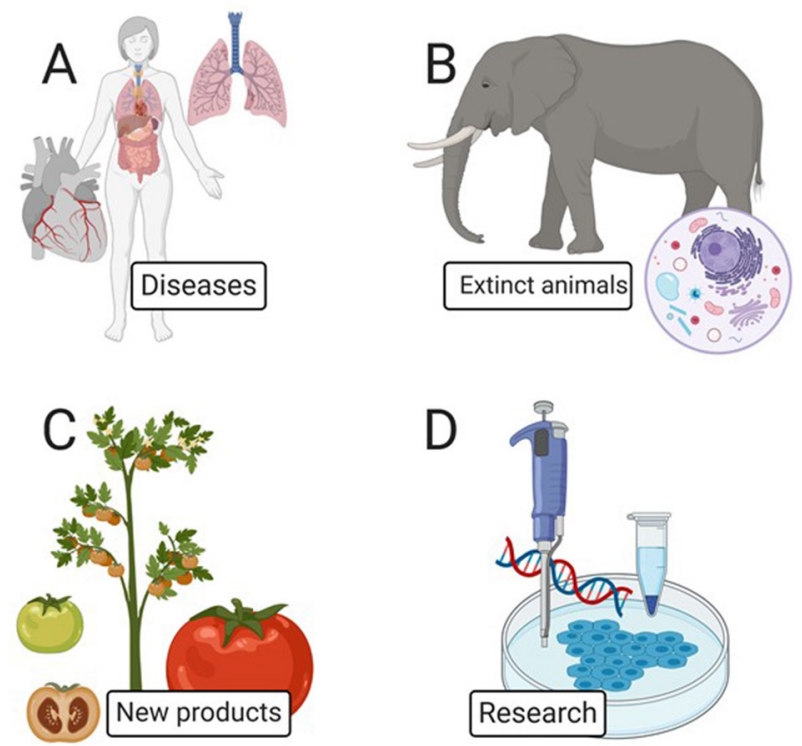

Figure 3

gene therapy and, since it is very new, it has not been fully tested on humans yet. If CRISPR/Cas9 gene therapy is shown to be safe for humans, it may be a promising way to help people suffering from diseases caused by mistakes in the DNA.

How cool would it be to see a wooly mammoth or a dinosaur walking around? Scientists believe they can use CRISPR/Cas9 to bring back extinct animals! Recently, scientists have successfully used CRISPR/Cas9 to change elephant cells to contain the DNA of the extinct wooly mammoth. These changes may help give elephants wooly mammoth traits, like wooly fur, which would help them survive in colder weather.

Companies can also use CRISPR/Cas9 to create new products. Imagine how tasty a spicy tomato would be! Researchers are exploring how to change tomato DNA so that it can produce capsaicin, the substance that makes chili peppers spicy. Salsas will never be the same! Other scientists are using CRISPR/Cas9 to help develop new varieties of plants like corn. These new varieties are able to grow even during extreme weather events like drought and heat waves caused by climate change.

\section{GREAT POWER CARRIES GREAT RESPONSIBILITY}

The applications for CRISPR/Cas9 are exciting, but the scientific community wants international rules to make sure that this technology is used in a safe and ethical manner. Ethics are the moral guidelines telling scientists that their work must protect public health and safety. Ethics ensure that all research respects human rights, animal welfare, 
and the law, so that scientists do not harm people, animals, or the environment. Because CRISPR/Cas9 is easy to use and does not cost much, it is hard to control who uses it and the purposes it is used for [3]. Scientists have decided that editing DNA is ethical if it is used to prevent people from getting sick or if it cures people who are already sick. But other questions remain, like whether it is safe to bring back a wooly mammoth. Do you think scientists should bring back extinct animals or modify foods? These are important questions!

Would you risk changing the DNA of your sibling before he or she was born, even if you knew a small mistake could trigger terrible consequences? Most of the scientific community does not support taking these risks. However, there has been some controversial CRISPR/Cas9 research involving human embryos. A scientist named He Jiankui, changed the DNA of two twins before they were born. This work was a worldwide scandal because he broke ethical rules by editing human embryos [4]. Scientists must consider that there are potential hazards of using this technology in an irresponsible way. For this reason, the World Health Organization and other organizations are now closely monitoring research on human genome editing, so that it is done in a responsible way.

\section{SUMMARY}

The CRISPR/Cas9 system keeps bacteria safe from viruses. Now, it is also being used by scientists to edit the DNA of organisms in the laboratory. The ability to change DNA in the laboratory allows us to learn more about how DNA works, to treat diseases, and to develop new products. There are many benefits of CRISPR/Cas9 technology if it is used in a responsible way. However, we must follow ethical rules to ensure no one is hurt in the process. Sometimes, new technological developments occur so fast that neither scientists nor policy makers can fully prepare. As scientists, we must always think about the risks of what we do as we strive to improve human lives.

\section{REFERENCES}

1. Hsu, P. D., Lander, E. S., and Zhang, F. 2014. Development and applications of CRISPR-Cas9 for genome engineering. Cell 157:1262-78. doi: 10.1016/j.cell. 2014.05.010

2. Zhang, S., Guo, F., Yan, W., Dai, Z., Dong, W., Zhou, J., et al. 2019. Recent advances of CRISPR/Cas9-based genetic engineering and transcriptional regulation in industrial biology. Front. Bioeng. Biotechnol. 7:459. doi: 10.3389/fb ioe.2019.00459

3. Brokowski, C., and Adli, M. 2019. CRISPR ethics: moral considerations for applications of a powerful tool. JMB 431:88-101. doi: 10.1016/j.jmb.2018.0 5.044 
4. Cyranoski, D. 2019. The CRISPR-baby scandal: what's next for human gene-editing. Nature. 566:440-42. doi: 10.1038/d41586-019-00673-1

SUBMITTED: 28 August 2020; ACCEPTED: 28 September 2021;

PUBLISHED ONLINE: 28 October 2021.

EDITED BY: Bahtiyar Yilmaz, Bern University Hospital, Switzerland

CITATION: Marnik EA, Bautista C, Drangowska-Way A, Simopoulos CMA and Merritt TJS (2021) CRISPR: A New Way for Scientists to Edit DNA. Front. Young Minds 9:600133. doi: 10.3389/frym.2021.600133

CONFLICT OF INTEREST: The authors declare that the research was conducted in the absence of any commercial or financial relationships that could be construed as a potential conflict of interest.

COPYRIGHT @ 2021 Marnik, Bautista, Drangowska-Way, Simopoulos and Merritt. This is an open-access article distributed under the terms of the Creative Commons Attribution License (CC BY). The use, distribution or reproduction in other forums is permitted, provided the original author(s) and the copyright owner(s) are credited and that the original publication in this journal is cited, in accordance with accepted academic practice. No use, distribution or reproduction is permitted which does not comply with these terms.

\section{YOUNG REVIEWERS}

\section{ABIGAIL, AGE: 11}

I am in the 5th grade. My hobbies include sewing, writing, and gaming. When I grow up I want to be an engineer.

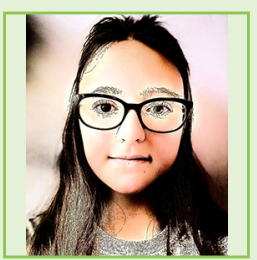

\section{MADDIE, AGE: 12}

My name is Maddie, and I am a student in Ms. Frantom's science class at Tappan Middle School in Ann Arbor, Michigan, in the USA. I swim competitively, ride horses in the summer, and run long distance for fun. I like science because you ask and answer a lot of questions. I love animals, singing, and nature, and in the future I want to travel the world.

\section{AUTHORS}

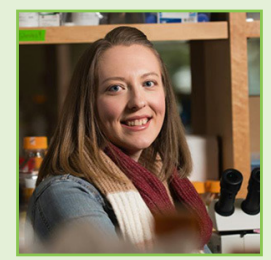

\section{ELISABETH A. MARNIK}

Elisabeth is an assistant professor of molecular biochemistry at Husson University. She uses small worms, called C. elegans, to understand how cells become other cells. She does this by using CRISPR to delete parts of the worm's DNA and studying the changes that result! In her free time, she loves running while pushing her toddler in the stroller, reading, and hiking. *marnike@husson.edu; torcid.org/0000-0002-5199-6835 


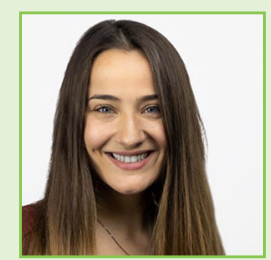

\section{CARLA BAUTISTA}

Carla is a Ph.D. candidate at Laval University in Quebec, Canada. She is interested in evolutionary biology but has also always been passionate about astronomy. She focused her career on astrobiology, since it combines both disciplines in the study of life in extreme environments, both on and off the planet. Currently, her research focuses on hybridization between species and how this process could help organisms adapt to extreme conditions. In her free time, she loves traveling, being in contact with nature, and dancing. c.bautistarourjc@gmail.com; †orcid.org/0000-0003-3456-6566
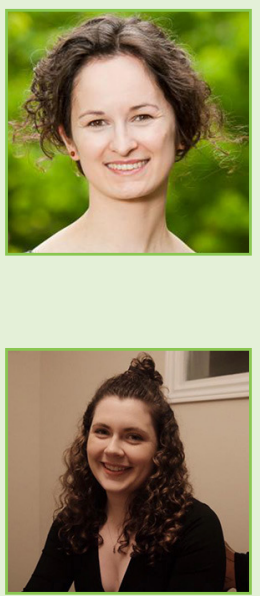

\section{ANNA DRANGOWSKA-WAY}

Anna is a Ph.D. student at the University of Virginia in Charlottesville, USA. She uses a small worm called $C$. elegans to understand how genes are regulated. She is specifically interested in how the genes that break down fats, called lipases, are regulated while worms are fasted or stressed. In her free time, she loves reading, traveling, and spending time with her family. aw5tz@avirginia.edu

\section{CAITLIN M. A. SIMOPOULOS}

Caitlin is a postdoctoral associate at the University of Ottawa in Ottawa, Canada. She is interested in creating and applying new computational tools for analyzing biological data. Currently, she is researching how the collection of bacteria, viruses, archaea, and fungi that live in our intestines can influence our health. Specifically, she is interested in how these microbial communities change when we take different medications. In her spare time, Caitlin loves to cycle around the beautiful Ottawa-Gatineau region, experiment with new recipes, and hang out with her two rescue cats. csimopou@uottawa.ca; ${ }^{\dagger}$ orcid.org/0000-0001-9832-7797

\section{THOMAS J. S. MERRITT}

Thomas is a professor of chemistry and biochemistry at Laurentian University, in Northern Ontario, Canada. He is interested in how changes in DNA lead to differences in an organism's traits and how DNA changes affect individuals differently. Much of his research is done using fruit flies, but some projects involve bacteria, and the lab is occasionally SNOLAB, a particle physics laboratory located $2 \mathrm{~km}$ underground. Outside of the lab, he spends as much time as he can on the water, paddling, rowing, and organizing a rowing program for people with disabilities. tmerritt@laurentian.ca 